\title{
Management of Hypersensitivity Reactions to Proton Pump Inhibitors: A Retrospective Experience
}

\author{
Seçil Kepil Özdemir ${ }^{a}$ Ferda Öner Erkekol ${ }^{b}$ Derya Ünale Suna Büyüköztürk ${ }^{\mathrm{e}}$ \\ Aslı Gelincik $^{e}$ Adile Berna Dursun ${ }^{f}$ Gül Karakayac Sevim Bavbek ${ }^{d}$ \\ ${ }^{a}$ Division of Allergy and Immunology, Dışkapı Yıldırım Beyazıt Training and Research Hospital, ${ }^{b}$ Division of Allergy \\ and Immunology, Department of Chest Diseases, Atatürk Chest Diseases and Thoracic Surgery Training and \\ Research Hospital, ' Division of Allergy and Immunology, Department of Chest Diseases, Hacettepe University \\ School of Medicine, and d Division of Allergy and Immunology, Department of Chest Diseases, University School \\ of Medicine, Ankara, ' Division of Allergy and Immunology, Department of Internal Medicine, Faculty of Medicine, \\ İstanbul University, İstanbul, and fDivision of Allergy and Immunology, Department of Internal Medicine, \\ Recep Tayyip Erdoğan University School of Medicine, Rize, Turkey
}

\section{Keywords}

Cross-reactivity $\cdot$ Drug allergy $\cdot$ Hypersensitivity $\cdot$ Proton pump inhibitors $\cdot$ Skin tests

\footnotetext{
Abstract

Background: We previously reported perfect specificity and low sensitivity of skin tests in proton pump inhibitor (PPI)induced immediate hypersensitivity reactions in a prospective multicenter study. Here, in a retrospective study, we aimed to further evaluate the diagnostic workup procedures and characteristics of the patients with suspected PPI hypersensitivity. Methods: This national multicenter study was conducted as a retrospective chart review of patients with a history of PPI-induced immediate hypersensitivity reaction. A total of 60 patients were included. Results of diagnostic workup procedures (standardized skin-prick, intradermal, and oral-provocation tests with PPIs) and the characteristics of the patients were analyzed. Results: Lansopra-
}

zole was the most commonly suspected drug with 41 patients (68.3\%), followed by pantoprazole in 12 patients $(20.0 \%)$, esomeprazole in $6(10.0 \%)$, rabeprazole in $4(6.7 \%)$, and omeprazole in 1 (1.7\%). Anaphylaxis (40 patients, 66.7\%) was the most common clinical presentation followed by urticaria (17 patients, $28.3 \%$ ). Diagnostic skin tests with the culprit PPI were positive in $13 / 26$ patients (50.0\%). Diagnostic oral-provocation tests were negative in $6 / 8$ patients; 5 of these 6 patients had skin test results with the culprit PPI, and all were negative. Ten patients had at least 1 cross-reactivity. Extensive cross-reactivity (between $>2$ PPIs) was detected in 4 patients. Conclusions: Lansoprazole was the most frequently implicated drug and anaphylaxis was the most frequent manifestation of $\mathrm{PPI}$-induced hypersensitivity reactions. Physicians should be aware of the possible crossreactivity among PPIs; however, a safe, alternative PPI can usually be detected by a thorough drug allergy workup.

(c) 2016 S. Karger AG, Basel

\section{KARGER}

(c) 2016 S. Karger AG, Basel

E-Mail karger@karger.com

www.karger.com/iaa
Correspondence to: Prof. Sevim Bavbek

Division of Allergy and Clinical Immunology, Department of Chest Diseases

Ankara University School of Medicine

TR-06100 Ankara (Turkey)

E-Mail bavbek@medicine.ankara.edu.tr 


\section{Introduction}

Proton pump inhibitors (PPIs) are one of the most commonly prescribed drugs and are widely used for treating acid-peptic diseases. Although hypersensitivity reactions due to PPIs are rare, several anaphylactic reactions have been reported [1-14]. The frequency of life-threatening reactions due to immediate hypersensitivity to PPIs and the common usage of these drugs make PPI hypersensitivity a significant problem.

Skin tests are useful in the diagnosis of immediate reactions to PPIs $[12,13]$. We previously reported perfect specificity and low sensitivity of skin tests in PPI-induced immediate hypersensitivity reactions in a prospective, multicenter study [12]. Previous trials and case reports suggested variable cross-reactivity patterns among PPIs $[1,6,7,12,13,15]$. In this retrospective, multicenter study, we aimed to evaluate the diagnostic workup procedures and characteristics of patients with suspected PPI hypersensitivity.

\section{Material and Methods}

In this multicenter study, we retrospectively reviewed charts from the period 2013-2016 of 60 patients who were referred to the allergy departments of 6 hospitals located in Ankara, İstanbul and Rize in Turkey, who had a history suggestive of an immediate hypersensitivity reaction after the administration of a PPI. Subjects with symptoms attributable to known side effects were not included. The study was approved by the Local Ethics Committee of the Ankara University School of Medicine.

The following data were collected: demographics, atopic status, clinical features, relevant medical history, and the results of skin testing and oral-provocation tests (OPTs) with PPIs. The severity of the reaction was assessed according to the Ring-Messmer scale [16]. Drug allergy workup was not uniform, because of the retrospective nature of the study. Diagnostic tests were performed according to the allergist's decision and the patient's consent. We used skin test concentrations proven in our previous study to be nonirritating in 30 healthy controls [12]. Skin-prick tests (SPTs) were performed with the undiluted commercial oral preparations of an omeprazole capsule ( $20 \mathrm{mg}$ ), a lansoprazole capsule (30 mg), a pantoprazole tablet $(40 \mathrm{mg})$, a rabeprazole tablet $(20 \mathrm{mg})$, and an esomeprazole tablet $(20 \mathrm{mg})$ by the prick method and $1 / 10$ and $1 / 1$ dilutions of injectable preparations of omeprazole $(4 \mathrm{mg} / \mathrm{mL})$, pantoprazole $(4 \mathrm{mg} / \mathrm{mL})$, and esomeprazole $(8 \mathrm{mg} / \mathrm{mL})$, along with positive (histamine $0.01 \%$ ) and negative (saline $0.9 \%$ ) controls. For the SPT, the tablets and micropellet capsules were ground in a mortar and diluted with $1 \mathrm{~mL}$ of $0.9 \% \mathrm{NaCI}$ according to the method described previously [17]. SPTs were performed on the volar forearm, and were read after $20 \mathrm{~min}$. A wheal reaction with a mean diameter of $3 \mathrm{~mm}$ greater than the negative control was considered positive. If SPTs were negative, intradermal tests (IDTs) were performed with the injectable preparations of omeprazole $(4 \mathrm{mg} / \mathrm{mL})$, pantoprazole $(4 \mathrm{mg} / \mathrm{mL})$, and esomeprazole

Management of Hypersensitivity

Reactions to PPIs
$(8 \mathrm{mg} / \mathrm{mL})$ at $1 / 1,000,1 / 100$, and $1 / 10$ dilutions. An amount of 0.03 $\mathrm{mL}$ of test solution was injected into the skin to produce a bleb. Readings were conducted after $15 \mathrm{~min}$ and were considered positive if the size of the initial wheal had increased by at least $3 \mathrm{~mm}$ in diameter and was surrounded by erythema.

After the skin tests, single-blind, placebo-controlled OPTs with the alternative PPIs which had displayed negative results in theskin tests, and/or diagnostic OPTs with the culprit PPI were performed in patients who gave their informed consent. During these tests, an omeprazole capsule $(5,10$, and $20 \mathrm{mg})$, a lansoprazole capsule (7.5, 15 , and $30 \mathrm{mg})$, a pantoprazole tablet $(5,10$, and $20 \mathrm{mg}$ ), a rabeprazole tablet $(5,10$, and $20 \mathrm{mg})$, and an esomeprazole tablet (5, 10 , and $20 \mathrm{mg}$ ) were administered each on different days at $30-\mathrm{min}$ intervals at increasing doses till reaching the full dose or the symptoms of a drug reaction occurred. The test results were accepted as positive if clinical signs (urticaria, angiooedema, bronchospasm, or other objective signs of the original drug reaction) or a $20 \%$ fall in $\mathrm{FEV}_{1}$ were observed.

The statistical analysis was performed using the SPSS program v18.0 (SPSS Inc., Chicago, IL, USA). The Fisher exact test was performed to compare the severity of the reactions between patients with negative and positive skin test results. A $p$ value of $<0.05$ was considered significant.

\section{Results}

\section{Subject Characteristics}

Sixty patients, i.e. 52 females $(86.7 \%)$ and 8 males (13.3\%); median (min-max) age $46.5(18-73)$ years, with a history suggesting a PPI-induced immediate hypersensitivity reaction were included in the study. Lansoprazole was the most commonly suspected drug in 41 patients (68.3\%), followed by pantoprazole in $12(20.0 \%)$, esomeprazole in $6(10.0 \%)$, rabeprazole in $4(6.7 \%)$, and omeprazole in $1(1.7 \%)$. Two patients $(3.3 \%)$ had a history of hypersensitivity reactions with unknown PPIs and 5 had had distinct reactions to different PPIs in separate episodes. The time interval between the last dose of the drug and the reaction was $\leq 1 \mathrm{~h}$ in 51 patients $(85.0 \%), 1-7 \mathrm{~h}$ in 6 $(10.0 \%)$, and was unknown in $3(5.0 \%$; median $0.5 \mathrm{~h}$, minmax: $0.05-7 \mathrm{~h})$. Anaphylaxis was the most common clinical presentation in 40 patients $(66.7 \%)$, followed by urticaria in $17(28.3 \%)$, a generalized erythematous rash in 2 (3.3\%), and isolated dyspnea in 1 (1.7\%). The severity of the reaction was grade 1 in 19 patients (31.7\%), grade 2 in $19(31.7 \%)$, and grade 3 in 22 (36.7\%). SPT results with common inhalant allergens were available in 31 patients (51.7\%), and 8 of these (25.8\%) had positivity on the SPTs.

\section{Drug Hypersensitivity Workup Results}

The median interval between the reaction and the diagnostic tests was 4 months (min-max: 0.5-60 months). 
Table 1. Clinical characteristics, skin test and OPT results (patients 1-21, cases with a definitive positive diagnosis, obtained with skin testing and/or OPTs with the suspected and/or an alternative PPI; patients 22-27, 6 cases in which OPTs with the suspected drug were negative)

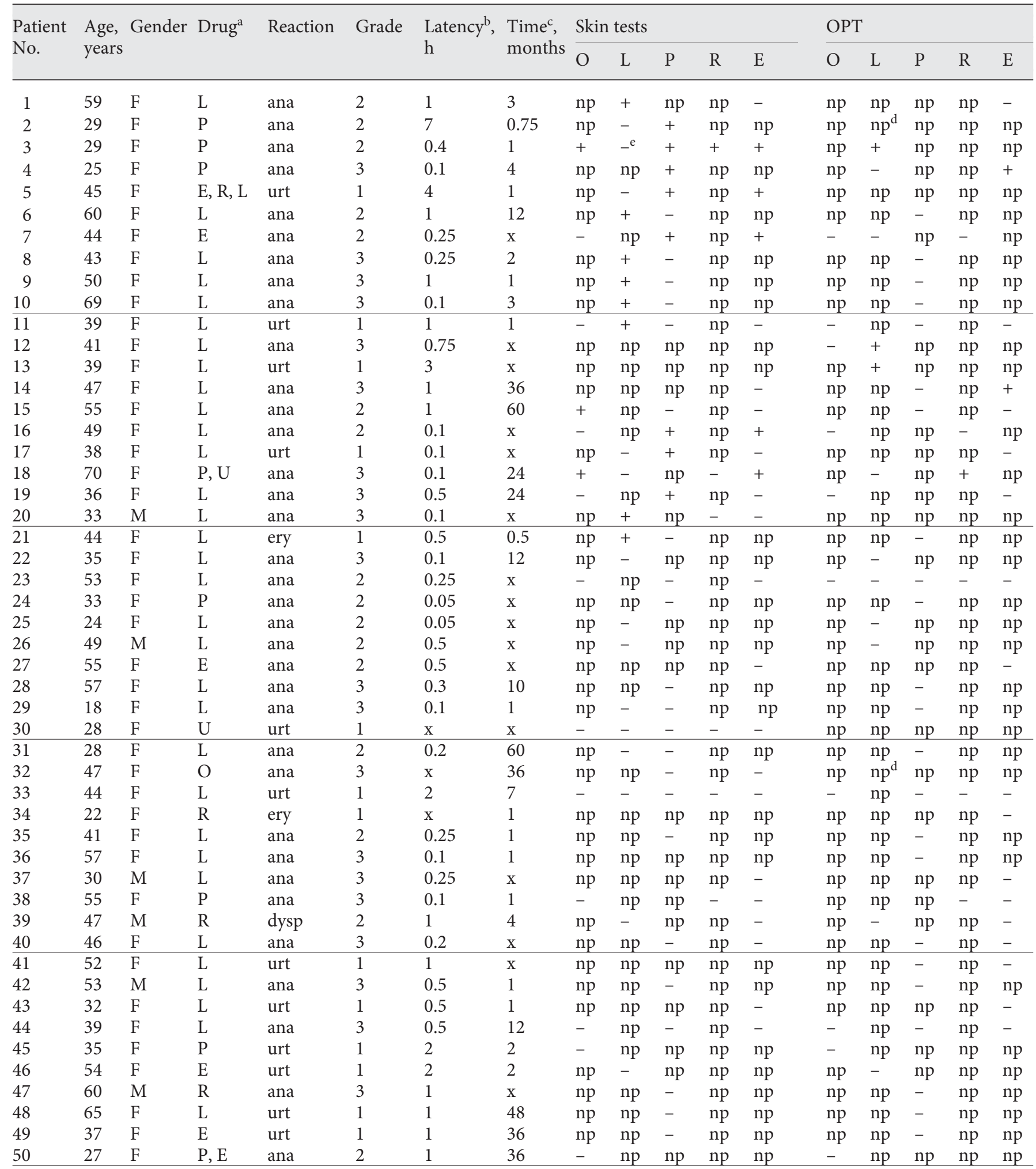


Table 1 (continued)

\begin{tabular}{|c|c|c|c|c|c|c|c|c|c|c|c|c|c|c|c|c|c|}
\hline $\begin{array}{l}\text { Patient } \\
\text { No. }\end{array}$ & $\begin{array}{l}\text { Age, } \\
\text { years }\end{array}$ & Gender & Drug $^{a}$ & Reaction & Grade & $\begin{array}{l}\text { Latency }{ }^{\mathrm{b}} \text {, } \\
\mathrm{h}\end{array}$ & $\begin{array}{l}\text { Time }{ }^{c} \text {, } \\
\text { months }\end{array}$ & \multicolumn{5}{|c|}{ Skin tests } & \multicolumn{5}{|c|}{ OPT } \\
\hline 52 & 53 & $\mathrm{~F}$ & $\mathrm{~L}$ & urt & 1 & 1 & $\mathrm{x}$ & np & np & - & np & $\mathrm{np}$ & np & np & - & $n p$ & $\mathrm{np}$ \\
\hline 53 & 47 & $\mathrm{~F}$ & $\mathrm{~L}$ & ana & 2 & 1 & $\mathrm{x}$ & $\mathrm{np}$ & - & - & $\mathrm{np}$ & $\mathrm{np}$ & np & $\mathrm{np}$ & - & $\mathrm{np}$ & $\mathrm{np}$ \\
\hline 54 & 55 & $\mathrm{~F}$ & $\mathrm{~L}$ & ana & 2 & 1 & 24 & $\mathrm{np}$ & $\mathrm{np}$ & - & $\mathrm{np}$ & $\mathrm{np}$ & np & $\mathrm{np}$ & - & $\mathrm{np}$ & $n p$ \\
\hline 57 & 56 & $\mathrm{~F}$ & $\mathrm{~L}, \mathrm{P}$ & ana & 3 & 1 & 3 & - & - & - & np & - & np & $\mathrm{np}$ & $\mathrm{np}$ & $n p$ & - \\
\hline 58 & 53 & $\mathrm{M}$ & $\mathrm{L}$ & ana & 2 & 0.5 & $\mathrm{x}$ & - & $\mathrm{np}$ & - & np & - & - & $n p$ & - & - & - \\
\hline 59 & 56 & $\mathrm{~F}$ & $\mathrm{~L}$ & ana & 3 & 0.5 & $\mathrm{x}$ & - & $\mathrm{np}$ & - & $\mathrm{np}$ & - & - & $\mathrm{np}$ & - & - & - \\
\hline 60 & 37 & M & $\mathrm{P}$ & urt & 1 & 1 & 5 & $\mathrm{np}$ & - & - & - & $\mathrm{np}$ & $\mathrm{np}$ & $\mathrm{np}$ & $\mathrm{np}$ & $\mathrm{np}$ & $\mathrm{np}$ \\
\hline
\end{tabular}

O, omeprazole; L, lansoprazole; P, pantoprazole; R, rabeprazole; E, esomeprazole; U, unknown PPI; OPT, oral provocation test; ana, anaphylaxis; urt, urticaria; dysp, dyspnea; ery, generalized erythematous rash; np, not performed; $\mathrm{x}$, unknown. ${ }^{\mathrm{a}}$ Suspected PPI. ${ }^{\mathrm{b}}$ Time interval between the last administration of the drug and the reaction. ${ }^{\mathrm{c}}$ Interval between the reaction and diagnostic tests. ${ }^{\mathrm{d}}$ OPT was not performed, but the patient could use the drug without a problem. ${ }^{\mathrm{e}}$ There was a $2 \times 2 \mathrm{~mm}$ edema in the skin-prick test with lansoprazole.

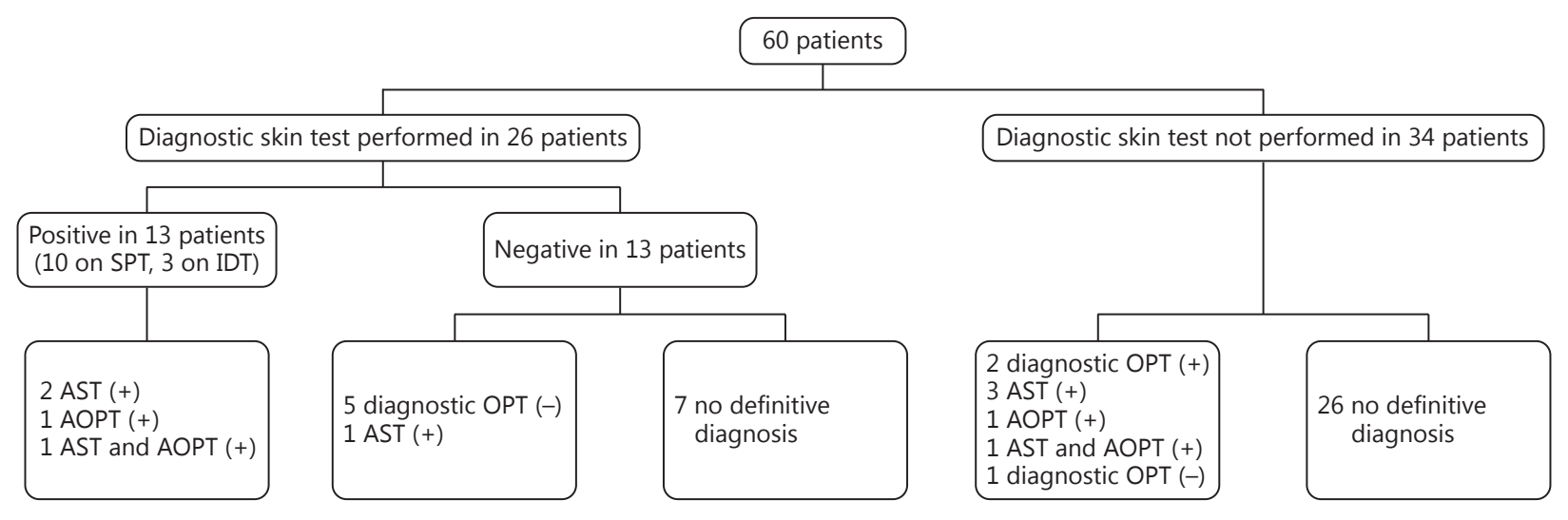

Fig. 1. Results of the drug allergy workup in 60 patients with symptoms suggestive of a hypersensitivity reaction after the administration of PPIs. AST, skin test with a PPI other than the suspected drug; AOPT, oral provocation test with a PPI other than the suspected drug; OPT, oral provocation test; SPT, skin-prick test; IDT, intradermal test.
The characteristics of the patients and the results of the skin tests and OPTs for the individual cases are shown in Table 1. Diagnostic skin tests with the suspected PPI were performed on $26 / 60$ patients. Diagnostic skin testing resulted as positive in $13 / 26$ patients $(50.0 \%$; Fig. 1 ; Table 2). Among these 13 patients, 10 had positivity on SPT, and 3 on IDT (Table 2). Diagnostic skin tests were positive for lansoprazole in $8 / 18$ patients $(44.4 \%)$, for panto- prazole in $3 / 6$ patients $(50.0 \%)$, and for esomeprazole in $2 / 3$ patients $(66.7 \%)$. The severity of the reaction was not statistically different between patients with negative and positive skin test results (4 patients with grade 1, 6 with grade 2 , and 3 with grade 3 , and 3 with grade 1,5 with grade 2 , and 5 with grade 3 , respectively; $p=0.673$ ). Because of the small number of patients with each grade, we combined grade 1 and grade 2 reactions while comparing 
Table 2. Skin test results of the 13 patients who showed positivity in diagnostic skin testing with the suspected PPI

\begin{tabular}{|c|c|c|c|c|c|c|}
\hline \multirow{2}{*}{$\begin{array}{l}\text { Patient } \\
\text { No. }\end{array}$} & \multirow[t]{2}{*}{ Drug $^{\mathrm{a}}$} & \multicolumn{5}{|l|}{ Skin tests } \\
\hline & & $\mathrm{O}$ & $\mathrm{L}$ & $\mathrm{P}$ & $\mathrm{R}$ & $\mathrm{E}$ \\
\hline 1 & $\mathrm{~L}$ & $\mathrm{np}$ & $+(30 \mathrm{mg} / \mathrm{mL}, \mathrm{SPT})$ & $\mathrm{np}$ & $\mathrm{np}$ & - \\
\hline 2 & $\mathrm{P}$ & $\mathrm{np}$ & - & $+(0.04 \mathrm{mg} / \mathrm{mL}, \mathrm{IDT})$ & np & $\mathrm{np}$ \\
\hline 3 & $\mathrm{P}$ & $+(0.004 \mathrm{mg} / \mathrm{mL}, \mathrm{ID})$ & $-{ }^{\mathrm{b}}$ & $+(40 \mathrm{mg} / \mathrm{mL}, \mathrm{SPT})$ & $+(20 \mathrm{mg} / \mathrm{mL}, \mathrm{SPT})$ & $+(0.008 \mathrm{mg} / \mathrm{mL}, \mathrm{IDT})$ \\
\hline 4 & $\mathrm{P}$ & $\mathrm{np}$ & $\mathrm{np}$ & $+(0.04 \mathrm{mg} / \mathrm{mL}, \mathrm{IDT})$ & $\mathrm{np}$ & $\mathrm{np}$ \\
\hline 5 & $\mathrm{E}, \mathrm{R}, \mathrm{L}$ & np & - & $+(40 \mathrm{mg} / \mathrm{mL}, \mathrm{SPT})$ & $\mathrm{np}$ & $+(20 \mathrm{mg} / \mathrm{mL}, \mathrm{SPT})$ \\
\hline 6 & $\mathrm{~L}$ & $\mathrm{np}$ & $+(30 \mathrm{mg} / \mathrm{mL}, \mathrm{SPT})$ & - & $\mathrm{np}$ & $\mathrm{np}$ \\
\hline 7 & $\mathrm{E}$ & - & $\mathrm{np}$ & $+(4 \mathrm{mg} / \mathrm{mL}, \mathrm{SPT})$ & $\mathrm{np}$ & $+(0.8 \mathrm{mg} / \mathrm{mL}, \mathrm{IDT})$ \\
\hline 8 & $\mathrm{~L}$ & $\mathrm{np}$ & $+(30 \mathrm{mg} / \mathrm{mL}, \mathrm{SPT})$ & - & np & $\mathrm{np}$ \\
\hline 9 & $\mathrm{~L}$ & $\mathrm{np}$ & $+(30 \mathrm{mg} / \mathrm{mL}, \mathrm{SPT})$ & - & $\mathrm{np}$ & $\mathrm{np}$ \\
\hline 10 & $\mathrm{~L}$ & $\mathrm{np}$ & $+(30 \mathrm{mg} / \mathrm{mL}, \mathrm{SPT})$ & - & np & $\mathrm{np}$ \\
\hline 11 & $\mathrm{~L}$ & - & $+(30 \mathrm{mg} / \mathrm{mL}, \mathrm{SPT})$ & - & $\mathrm{np}$ & - \\
\hline 20 & $\mathrm{~L}$ & $\mathrm{np}$ & $+(30 \mathrm{mg} / \mathrm{mL}, \mathrm{SPT})$ & $\mathrm{np}$ & - & - \\
\hline 21 & $\mathrm{~L}$ & np & $+(30 \mathrm{mg} / \mathrm{mL}, \mathrm{SPT})$ & - & $\mathrm{np}$ & $\mathrm{np}$ \\
\hline
\end{tabular}

O, omeprazole; L, lansoprazole; P, pantoprazole; R, rabeprazole; E, esomeprazole; IDT, intradermal test; np, not performed; SPT, skin-prick test. ${ }^{\text {a }}$ Suspected PPI. ${ }^{\text {b }}$ There was a $2 \times 2 \mathrm{~mm}$ edema on the SPT with lansoprazole.

the severity of the reactions between patients with negative and positive skin test results.

Of the 13 patients with negative diagnostic skin test results, 5 had diagnostic OPTs with the suspected PPI and all were negative, and 1 had positivity on a skin test with a PPI other than the suspected drug (Table 1; patient No. 17). Among the 34 patients on whom diagnostic skin tests with the suspected PPI were not performed, 2 had positive and 1 had negative diagnostic OPT results with the culprit PPI, and 5 had positive results with an alternative PPI on skin testing and/or OPTs (Fig. 1).

Diagnostic OPTs with the suspected PPIs were performed in 8 patients (Table 1 ). These were negative in $6 / 8$ patients (75.0\%), and 5 of these 6 patients had diagnostic skin test results with the culprit PPI, all of which were negative. Of these 6 patients with a negative diagnostic OPT, 5 had a history of grade 2 reactions, and one had grade 3 reactions. Of the 2 patients with positive diagnostic OPTs with the suspected PPI, 1 had a history of grade 1 reactions, and 1 had grade 3 reactions. The reactions which occurred during the diagnostic OPTs were of grade 1 severity in 1 patient and grade 3 in the other patient. The latency between the last provocation dose and the reaction was $2 \mathrm{~h}$ in the patient with the grade 1 reaction and was not noted in the patient with the grade 3 reaction. These reactions showed a full recovery shortly after treatment. OPTs with PPIs other than the culprit PPI in the clinical history were performed on $47 / 60$ patients $(78.3 \%)$.
Positivity rates were as follows: $0 / 11$ for omeprazole, $1 / 6$ (16.7\%) for lansoprazole, 0/27 for pantoprazole, $1 / 7$ (14.3\%) for rabeprazole, and 2/21 (9.5\%) for esomeprazole.

A definitive diagnosis was obtained with skin testing and/or OPTs with the suspected and/or alternative PPI in 27 patients (positive in 21 patients and negative in 6; Fig. 1; Table 1). Diagnostic skin tests with the suspected PPI were performed in 19 of these 27 patients, i.e. in 14 with confirmed PPI hypersensitivity and in 5 with a negative diagnostic OPT result. The result was positive in 13/14 patients with confirmed PPI hypersensitivity and all 5 patients with a negative diagnostic OPT result showed a negative result on the skin test with the suspected PPI.

We evaluated cross-reactivity in 21 patients in whom a positive definitive diagnosis was established. Ten patients had at least 1 cross-reactivity. Pantoprazole-esomeprazole cross-reactivity was detected in 2, lansoprazolepantoprazole cross-reactivity in 2, lansopraloze-omeprazole cross-reactivity in 1, and lansoprazole-esomeprazole cross-reactivity in 1. Extensive cross-reactivity (i.e. between $>2$ PPIs) was detected in 4 patients. Of these 4 , the first had a lansoprazole-pantoprazole-esomeprazole reactivity, and tolerated omeprazole and rabeprazole. The second had reactivity for the whole PPI group. The third had an omeprazole-pantoprazole-rabeprazole-esomeprazole hypersensitivity but tolerated lansoprazole, and 
the last had a lansoprazole-pantoprazole-rabeprazoleesomeprazole hypersensitivity. In the last case, no OPT with omeprazole was performed, so we could not exclude hypersensitivity for the whole group.

\section{Discussion}

In this study, we reported the clinical characteristics and allergy workup results of 60 patients with suspected PPI hypersensitivity. The major causative drug was lansoprazole in 41 patients (68.3\%). A similar finding was observed in our previous study in which lansoprazole was the suspected drug in $80 \%$ of the cases (52/65 patients) [12]. Another large trial showed a different distribution of the frequency of PPI involvement; Bonadonna et al. [13] reported a more frequent involvement with esomeprazole $(30 \%)$ followed by lansoprazole $(26.4 \%)$. The strikingly frequent involvement of lansoprazole in both of our studies may be due to the prescription patterns in Turkey, since lansoprazole is the most commonly prescribed PPI in our country. A current review, in which 199 immediate reactions to PPIs have been evaluated, supported the most frequent involvement of lansoprazole $(n=77)$ in immediate hypersensitivity reactions due to PPIs [18]. In this study, $25.8 \%$ of the cases with an available common-inhalant SPT result were atopic, but since we did not have a control group, atopy was not analyzed as a risk factor for PPI hypersensitivity.

In our previous study, we analyzed the diagnostic value of skin tests in a group of 38 patients with PPI-induced immediate-type hypersensitivity reactions and in 30 healthy controls. The specificity and positive predictive value of the tests were both $100 \%$, and the sensitivity and negative predictive value were 58.8 and $70.8 \%$, respectively [12]. In this study, we could confirm a definitive diagnosis regarding PPI hypersensitivity with skin testing and/or OPTs with the suspected and/or alternative PPIs in 27 patients. Diagnostic skin tests with the suspected PPI were performed in 19 of these 27 patients (in 14 patients with confirmed PPI hypersensitivity and 5 with a negative diagnostic OPT result). Diagnostic skin testing resulted as positive in 13/14 patients with confirmed PPI hypersensitivity. All 5 patients with a negative diagnostic OPT result showed a negative result on the skin test with the suspected PPI. In another large study, Bonadonna et al. [13] analyzed 53 patients with immediate reactions to PPIs and reported the diagnostic performance of skin tests versus OPTs in patients with grade 1 and 2 reactions. They reported $100 \%$ spec-

Management of Hypersensitivity

Reactions to PPIs ificity, $100 \%$ positive predictive value, $91.9 \%$ negative predictive value, and $61.3 \%$ sensitivity in their study population.

In this study, we used skin test concentrations that had been proved to be nonirritating in 30 control subjects in our previous study [12]. To the best of our knowledge, false skin test positivity to PPIs confirmed by challenge tests has not been reported so far. In the study by Bonadonna et al. [13], 4/12 patients who exhibited positive skin tests with the suspected PPI underwent an OPT, and the result was positive in all cases. Additionally, there are case reports showing confirmation of skin test positivity with oral challenge tests with PPIs $[1-3,6]$. Based on these data, we did not perform confirmatory OPTs in patients with skin test positivity to the culprit or alternative PPIs. Similarly, in a recent review, the authors suggest that, given the very high specificity and PPV of skin testing in cases of suspected IgE-mediated reactions, OPTs should be performed only in cases of negative results, to rule out the diagnosis [19].

Anaphylaxis was the most common clinical presentation of PPI hypersensitivity (66.7\%) and hypotension occurred in $20 \%$ of the cases in this study. Anaphylaxis was also frequent in the previous reports $[12,19,20]$. The latency time between the last drug intake and the reaction was $\leq 1 \mathrm{~h}$ in $85 \%$ and $1-7 \mathrm{~h}$ in $10 \%$ of the study patients. In 1 of our patients with a history of anaphylaxis with pantoprazole, the latency time was $7 \mathrm{~h}$. The IDT with pantoprazole was positive in this patient, suggesting an immediate hypersensitivity mechanism. There are case reports of delayed anaphylaxis to PPIs that begin up to $24 \mathrm{~h}$ after drug intake [11,21, 22]. This may be explained by the enteric coating of the PPIs which may cause a delay in the onset of the reaction. It was also hypothesized that polymorphisms in the cytochrome P450 CYP2C19 gene (associated with a poor metabolizer phenotype) might be related to anaphylaxis timing [21].

Cross-reactivity exists among the various PPIs; however, the patterns of cross-reactivity are variable [23]. PPIs have a benzimidazole ring and a pyridine ring. Omeprazole, esomeprazole and pantoprazole have changes in their benzimidazole rings whereas lansoprazole and rabeprazole have modification in their pyridine rings [19]. Four general patterns of cross-reactivity, which could be explained by the chemical structure of PPIs, have been identified based on the published articles: wholegroup hypersensitivity, omeprazole-esomeprazole-pantoprazole hypersensitivity, lansoprazole-rabeprazole hypersensitivity, and selective sensitization to a single PPI [19]. Although we could not perform a full analysis of 
cross-reactivity with all PPIs in most of our cases, 10/21 patients with a positive definitive diagnosis showed at least 1 cross-reactivity. Four of these may fit to the patterns described, i.e. 1 with whole-group sensitivity, 1 with possible whole-group sensitivity, 1 with pantoprazoleesomeprazole cross-reactivity (and no OPT with omeprazole), and 1 with pantoprazole-esomeprazole cross-reactivity. However, the cross-reactivity in the remaining 6 cases (lansoprazole-pantoprazole in 2 patients, lansopraloze-omeprazole in 1, lansoprazole-esomeprazole in 1, lansoprazole-pantoprazole-esomeprazole in 1, and omeprazole-pantoprazole-rabeprazole-esomeprazole in 1) cannot be explained by these patterns. In our previous study, despite the molecular differences, the most common pattern of cross-reactivity was between lansoprazole and pantoprazole [12]. Cross-reactivity of omeprazolelansoprazole $[6,12]$, omeprazole-pantoprazole-lansopra- zole [1, 15], and omeprazole-rabeprazole-pantoprazole [20] has also been reported.

In conclusion, lansoprazole was the most frequently implicated drug and anaphylaxis was the most frequent manifestation of PPI-induced hypersensitivity reactions. Delayed-onset PPI reactions with a suspected immediate hypersensitivity mechanism might be possible. We strongly recommend skin testing with PPIs before performing OPTs. Physicians should be aware of the possible cross-reactivity among PPIs; however, a safe, alternative PPI can usually be detected by a thorough drug allergy workup.

\section{Disclosure Statement}

None of the authors has conflicts of interest pertaining to this study.

\section{References}

1 González P, Soriano V, López P, Niveiro E: Anaphylaxis to proton pump inhibitors. Allergol Immunopathol (Madr) 2002;30:342343.

2 Pérez Pimiento AJ, Prieto Lastra L, Rodríguez Cabreros MI, González Sánchez LA, Mosquera MR, García Cubero A: Hypersensitivity to lansoprazole and rabeprazole with tolerance to other proton pump inhibitors. J Allergy Clin Immunol 2006;117:707-708.

3 Demirkan K, Bozkurt B, Karakaya G, Kalyoncu AF: Anaphylactic reaction to drugs commonly used for gastrointestinal system diseases: 3 case reports and review of the literature. J Investig Allergol Clin Immunol 2006; 16:203-209.

4 Garrido S, Cumplido JA, Rábano A, Martíez D, Blanco C, Carrillo T: Allergy to proton pump inhibitors: diagnosis and assessment of cross-reactivity. J Investig Allergol Clin Immunol 2008;18:140-141.

5 Vovolis V, Koutsostathis N, Stefenaki E: IgEmediated anaphylaxis to proton pump inhibitors - cross-reacting study. Allergy 2008;63: 1251-1252.

6 Lobera T, Navarro B, Del Pozo MD, González I, Blasco A, Escudero R, et al: Nine cases of omeprazole allergy: cross-reactivity between proton pump inhibitors. J Investig Allergol Clin Immunol 2009;19:57-60.

7 Sobrevia Elfau MT, Garcés Sotillos M, Ferrer Clavería L, Segura Arazuri N, Monzón Ballarin S, Colás Sanz C: Study of cross-reactivity between proton pump inhibitors. J Investig Allergol Clin Immunol 2010;20:157-161.
8 Pérez-Ezquerra PR, Morillas LS, Martínez JJ, Fernández DG, Gomez-Tebleque Mdel P, Alvarez AS, et al: Anaphylaxis to omeprazole. Cross-reactivity with the other proton pump inhibitors. Allergol Immunopathol (Madr) 2011;39:54.

9 Vovolis V, Christogianni K, Koutsostathis N: Immunoglobulin E-mediated anaphylaxis to rabeprazole. J Investig Allergol Clin Immunol 2010;20:360-361.

10 Abdul Razzak E, Tomás M, Tornero P, Herrero T: Nine cases of allergy to omeprazole. J Investig Allergol Clin Immunol 2012;22:228230.

11 Aksu K, Kurt E: Anaphylaxis to lansoprazole with tolerance to omeprazole. Allergol Immunopathol (Madr) 2012;40:393-394.

12 Kepil Özdemir S, Yılmaz I, Aydın O, Büyüköztürk S, Gelincik A, Demirtürk M, Erdoğdu D, Cömert Ş, Erdoğan T, Karakaya G, Kalyoncu AF, Öner Erkekol F, Dursun AB, Misırlıgil Z, Bavbek S: Immediate-type hypersensitivity reactions to proton pump inhibitors: usefulness of skin tests in the diagnosis and assessment of cross-reactivity. Allergy 2013;68: 1008-1014.

13 Bonadonna P, Lombardo C, Bortolami O, Bircher A, Scherer K, Barbaud A, et al: Hypersensitivity to proton pump inhibitors: diagnostic accuracy of skin tests compared to oral provocation test. J Allergy Clin Immunol 2012;130:547-549.

14 Mota I, Gaspar Â, Chambel M, Morais-Almeida M: Anaphylaxis induced by proton pump inhibitors. J Allergy Clin Immunol Pract 2016;4:535-536.
15 Garmendio Zallo M, Sánchez Azkarate A, Kraemer Mbula R, Liarte Ruano I, Nuñez Hernan$\operatorname{dez}$ A, Cid de Rivera C: Cross reactivity among proton pump inhibitors: does it exists? Allergol Immunopathol (Madr) 2004;32:92-95.

16 Ring J, Messmer K: Incidence and severity of anaphylactoid reactions to colloid volume substitutes. Lancet 1977;1:466-469.

17 Brockow K, Romano A, Blanca M, Ring J, Picher W, Demoly P: General considerations for skin test procedure in the diagnosis of drug hypersensitivity. Allergy 2002;57:45-51.

18 Otani IM, Banerji A: Immediate and delayed hypersensitivity reactions to proton pump inhibitors: evaluation and management. Curr Allergy Asthma Rep 2016;16:17.

19 Lombardo C, Bonadonna P: Hypersensitivity reactions to proton pump inhibitors. Curr Treat Options Allergy 2015;2:110-123.

20 Sánchez-Morillas L, Pérez-Ezquerra PR, Mendiola RG, Úbeda PGT, Álvarez AS, Laguna-Martínez JJ: Eleven cases of omeprazole hypersensitivity: diagnosis and study of crossreactivity. J Investig Allergol Clin Immunol 2014;24:122-141.

21 Kollmeier AP, Eddleston J, Zuraw BL, Christiansen SC: Recurrent idiopathic anaphylaxis linked to pantoprazole. J Allergy Clin Immunol 2004;S310.

22 Tayman C, Mete E, Catal F, Tonbul A: Hypersensitivity reaction to omeprazole in a child. J Investig Allergol Clin Immunol 2009;19:64-79.

23 Bose S, Guyer A, Long A, Banerji A: Evaluation and management of hypersensitivity to proton pump inhibitors. Ann Allergy Asthma Immunol 2013;111:452-457. 